\title{
Application of garnet geothermobarometry to southern African kimberlites
}

\author{
Menzies, A.H. ${ }^{1}$ and Baumgartner, M.C. ${ }^{2}$
}

1. Department of Geological Sciences, University of Cape Town, Rondebosch, 7700, South Africa.

2. Mineral Services, P.O. Box 527, Howard Place, 7450, South Africa.

Ryan et al. (1996) propose a method for determining a geotherm from the major and trace element compositions of a population of discrete garnet xenocrysts sampled from the lithosphere by kimberlites and other volcanic rocks. The procedure involves obtaining a temperature using the nickel in garnet thermometer $\left(\mathrm{T}_{\mathrm{Ni}}\right)$ followed by a pressure calculation using the garnet barometer $\left(\mathrm{P}_{\mathrm{Cr}}\right)$. This calculation involves an iterative process in which a theoretical orthopyroxene (in equilibrium with the garnet) is derived from the garnet's major element composition and its temperature of equilibration. According to Ryan et al. (1996), the calculated value is a minimum pressure because one cannot ascertain whether it is in equilibrium with chromite and hence, chrome saturated. The garnet geotherm is thus derived from the locus of maximum $\mathrm{P}_{\mathrm{Cr}}$ for each $\mathrm{T}_{\mathrm{Ni}}$.

In this study, the "garnet geotherm" method of Ryan et al. (1996) is applied to garnets from various Kaapvaal craton kimberlites. The localities investigated include the Group I kimberlites of the Kimberley Group (De Beers, Wesselton, Du Toitspan) and Monastery, and the Group II kimberlites of Newlands, Roberts Victor and Finsch. In addition to Ryan et al. (1996), the experimentally calibrated $\mathrm{T}_{\mathrm{Ni}}$ of Canil (1994) is used for comparison. Major element compositions were obtained using the electron microprobe (EMP) at the University of Cape Town, and trace elements using the proton microprobe (PMP) at the National Accelerator Center, Cape Town. The implied garnet geotherms of both Ryan and Canil are compared to geotherms derived from peridotitic xenolith suites from most of the localities. The xenolith geotherms were derived by applying a variety of geothermobarometers to data from the UCT Kimberlite Research Group, or from data obtained in the literature. With the exception of the Kimberley group, the kimberlites analysed in this study are all diverse in space and time, and it is therefore not possible to combine all the garnet pressures and temperatures to construct a single garnet geotherm.

The derived garnet geotherms for the three methods applied vary from 35 to $40 \mathrm{~mW} / \mathrm{m}^{2}$. Table 1 contains a summary of the results from the various localities. The implied garnet geotherms vary depending on whether $\mathrm{T}_{\mathrm{Ni}}$ (Ryan) or $\mathrm{T}_{\mathrm{Ni}}$ (Canil) is combined with $\mathrm{P}_{\mathrm{Cr}}$. In general, relatively few points in P-T space define the garnet geotherm and thus in many cases the value inferred is somewhat subjective. The garnet geotherm is commonly defined by both G9 and G10 garnets with temperatures less than $1200{ }^{\circ} \mathrm{C}$. Below $1200{ }^{\circ} \mathrm{C}, \mathrm{T}_{\mathrm{Ni}}$ (Canil) is greater than $\mathrm{T}_{\mathrm{Ni}}$ (Ryan). The absolute difference between these two geothermometers increases as the nickel content in the garnet decreases. Because the $\mathrm{P}_{\mathrm{Cr}}$ calculation is temperature dependent, the pressures calculated using the $\mathrm{T}_{\mathrm{Ni}}$ (Canil) are different. The combination of $\mathrm{T}_{\mathrm{Ni}}$ (Canil) and $\mathrm{P}_{\mathrm{Cr}}$ define a garnet geotherm higher than that of $\mathrm{T}_{\mathrm{Ni}}(\mathrm{Ryan})$ and $\mathrm{P}_{\mathrm{Cr}}$. The lower the implied garnet geotherm of Ryan et al. (1996), the greater the difference in the implied geotherm of Canil (1994). Figures $1 \mathrm{a}$ and $1 \mathrm{~b}$ show this difference for the Kimberley Group of kimberlites. The garnet geotherms derived using $\mathrm{T}_{\mathrm{Ni}}$ (Canil) correspond closer to the xenolith geotherms than do the garnet geotherms derived using $\mathrm{T}_{\mathrm{Ni}}(\mathrm{Ryan})$. It should be noted that the minimum temperature possible using $\mathrm{T}_{\mathrm{Ni}}$ (Canil) is approximately $850^{\circ} \mathrm{C}$. This effectively "compresses" the garnet temperature range relative to $\mathrm{T}_{\mathrm{Ni}}$ (Ryan) and the inferred garnet geotherm is thus defined over a narrower P-T range. 
Table 1 Various garnet and xenolith geotherms for selected southern African locations

\begin{tabular}{|c|c|c|c|c|c|c|c|}
\hline Kimberlite & $\begin{array}{l}\text { Age }^{\mathrm{T}} \\
\text { (Ma) }\end{array}$ & Group & $\begin{array}{c}\mathrm{T}_{\mathrm{Ni}}(\text { Ryan }) \\
\text { Garnet } \\
\text { Geotherm } \\
\left(\mathrm{mW} / \mathrm{m}^{2}\right)\end{array}$ & $\begin{array}{c}\mathbf{T}_{\mathrm{Ni}} \text { (Canil) } \\
\text { Garnet } \\
\text { Geotherm } \\
\left(\mathrm{m} \mathrm{W} / \mathrm{m}^{2}\right)\end{array}$ & $\begin{array}{c}\text { Xenolith } \\
\text { Geotherm } \\
\left(\mathrm{mW} / \mathrm{m}^{2}\right)\end{array}$ & $\begin{array}{l}\text { Temperature } \\
\text { of start of } \\
\text { diamond } \\
\text { stability }\end{array}$ & $\begin{array}{c}\text { Depth of } \\
\text { start of } \\
\text { diamond } \\
\text { stability }\end{array}$ \\
\hline Kimberley Group & 77 to 92 & I & 37 & 40 & 39 & 1030 & 140 \\
\hline Finsch & 91 to 118 & II & $39 ?$ & 39 & 40 & 980 & 135 \\
\hline Monastery & 90 & I & 38 & 40 & 40 & 1030 & 140 \\
\hline Newlands & 114 & II & 35 & 37 & 37 & 900 & 125 \\
\hline Roberts Victor & 92 to 128 & II & 35 & 37 & & 900 & 125 \\
\hline
\end{tabular}

Age data compiled from Gurney et al. (1991) and Smith et al. (1985).

The garnet temperature range (for both $\mathrm{T}_{\mathrm{Ni}}$ (Ryan) and $\mathrm{T}_{\mathrm{Ni}}$ (Canil)) varies between locations. In general, however, the temperatures range up to $1200{ }^{\circ} \mathrm{C}$, after which the garnets become scarce. This is illustrate din the Newlands example presented in Figure 2. There does not appear to be a noticeable difference in temperature range between Group I and Group II kimberlites. Temperatures calculated for both the G9 and G10 garnets generally overlap although the G9's typically have temperatures spanning a greater range. The derived geotherms for Group II kimberlites are lower than those obtained for Group I kimberlites, an observation consistent with that previously described by Griffin and Ryan (1995). However, the garnet geotherms determined for individual locations analysed both in this study and in the study by Griffin and Ryan (1995), are different.

Fifteen of the samples analysed from Newlands are diamond-bearing garnet macrocrysts (described in detail by Menzies, 1998). All the diamond-bearing garnet macrocrysts have $\mathrm{T}_{\mathrm{Ni}}(\mathrm{Ryan})$ and $\mathrm{T}_{\mathrm{Ni}}$ (Canil) that fall within the diamond stability field using geotherms derived from either of the two combinations. This observation does indicate the potential usefulness of this method in obtaining a better understanding of the nature of the peridotitic garnet population.

Figure 1a:

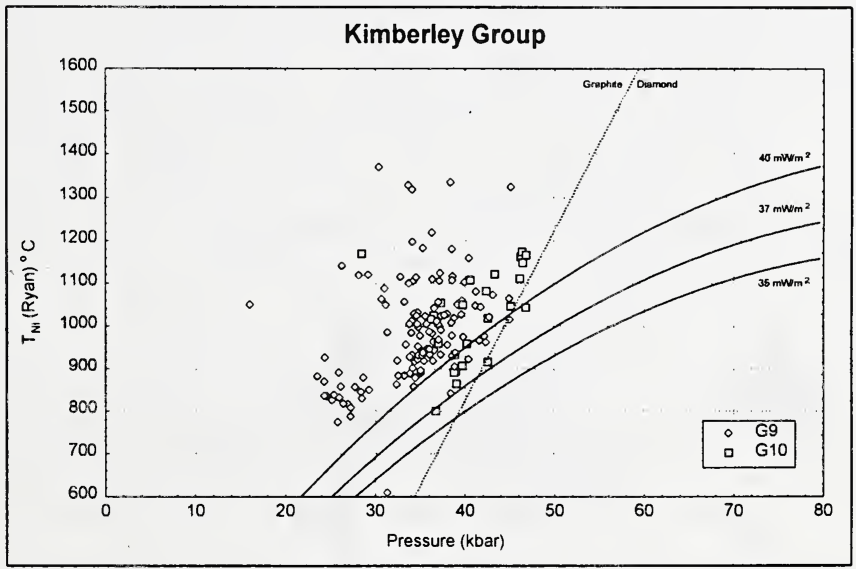




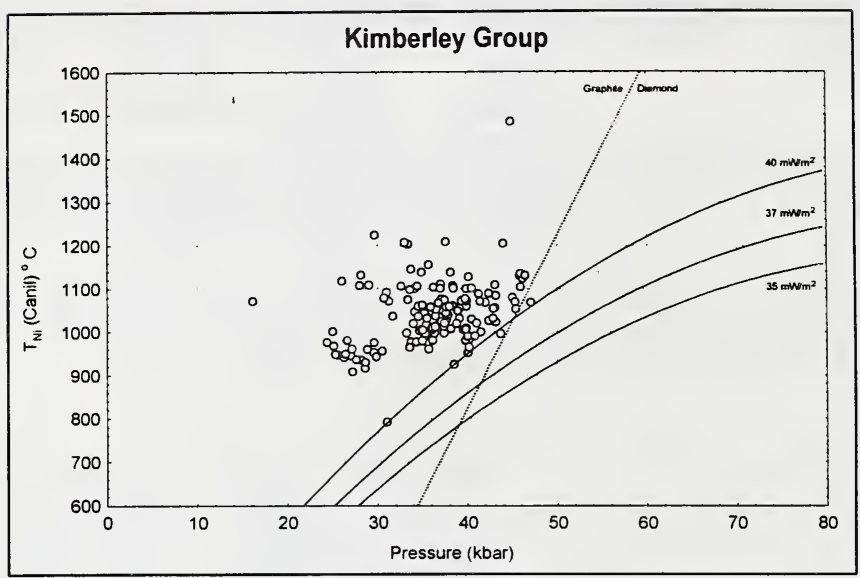

Figure 1b:

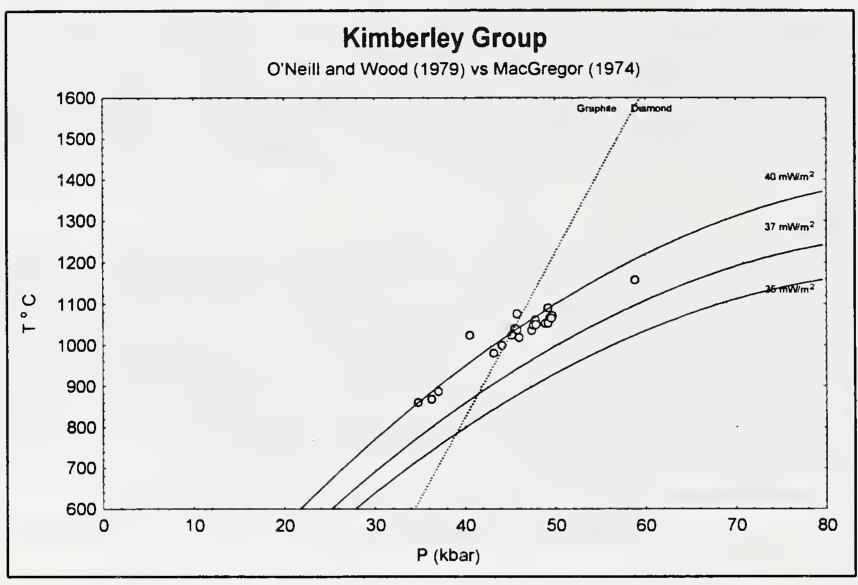

Figure 1c

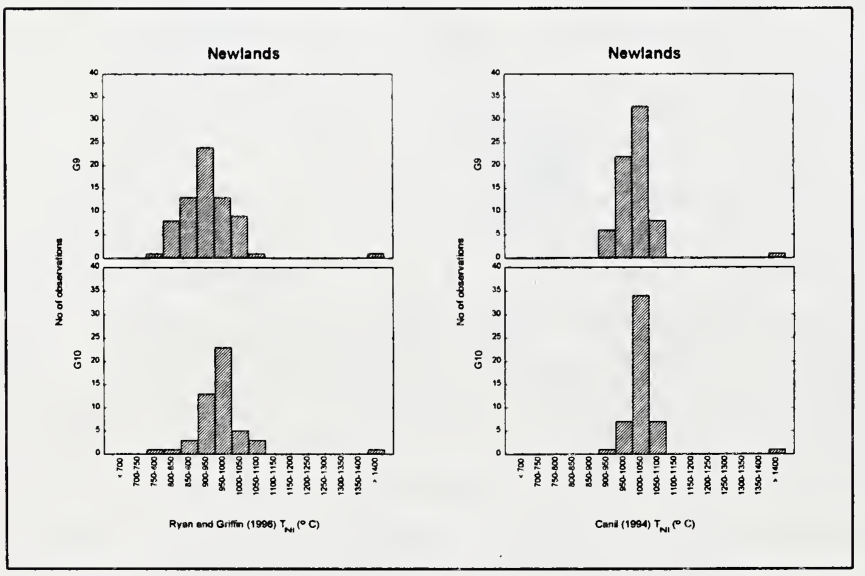

Figure 2 